\title{
MRDC Monitor Farms - using information
}

A.P. RHODES' and M.D. ASPIN ${ }^{2}$

'Agriculture New Zealand, PO Box 288, Dannevirke ${ }^{2}$ Meat Research and Development Council, Wellington

\section{Abstract}

An industry survey indicated a concern that the results of existing research were not getting across to potential adopters. In response to this situation, the Meat Research and Development Council sponsored a monitor farm programme which operated on 24 farms throughout New Zealand. Key components of the programme were the monitor farmer and farm, community group, and facilitator. Factors judged critical to the success of the programme were the need for local ownership of the programme, development of quality information, and the establishment of a partnership of skills, expertise and experience. Preliminary surveys indicate a high level of farmer endorsement of the programme. Level of involvement by community group members has exceeded that set initially. Further analysis is required to identify the impact of the programme on farm business performance and the application of technology in New Zealand farm businesses.

Keywords: community group, information, monitor farm, technology transfer

\section{Introduction}

New Zealand farmers are recognised for their innovativeness and adaptiveness, attributes that have been important in supporting the pastoral industry through its development. Research, and the adoption of new technology by farmers have been features that have contributed to the productivity of the industry.

A study by Scobie \& Eveleens (1986) examined the contribution of agricultural research in New Zealand, and concluded that the return on research comes over an extended period; in fact the best estimate is 23 years. But the size of benefits is such that the annual real rate of return to investment is around $30 \%$. This is a substantial return, and is well above the rate of $10 \%$ used as a guide to the minimum acceptable return to public investment. Although favourable, two important parameters influence this rate of return.

Although the volume and value of pastoral products exported benefits New Zealand, adoption of the results of research is very dependent on the benefits that accrue to individual pastoral farmers.
Secondly, the level of benefit obtained depends on both the proportion of a community implementing technology, and the rate at which the adoption occurs (Scobie \& Eveleens).

In 1989, in response to government changes in funding for research and development, the NZ Meat Producers Board reviewed the research and development needs of the meat industry. The review identified a need for national co-ordination of meat industry research and development.

The Board established the Meat Research and Development Council (MRDC) to facilitate its research and development strategy.

In 1990 the Council surveyed a wide range of industry participants to identify their research needs. This survey identified a concern that the results of existing research were not getting across to people. The results were either not known, or people could not see how to apply them to their own situation (Figure 1).

Figure 1 The difference between available technology and its adoption - the technology gap

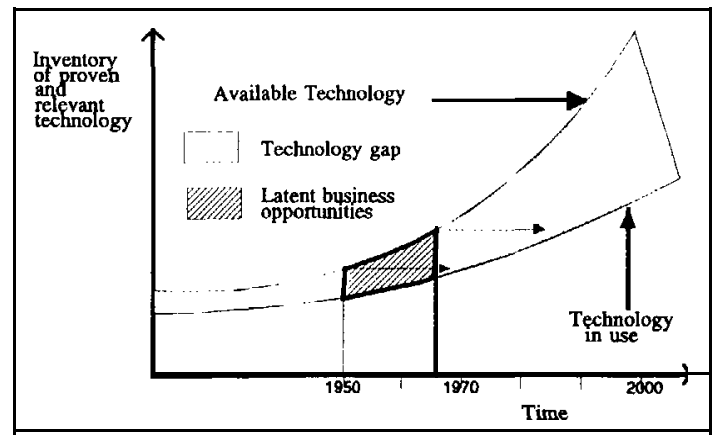

\section{M ethod}

In February 1991 the MRDC invited "science providers" to submit proposals for meat-related research. Following a series of workshops, an information transfer programme involving monitor farms was evolved and the MRDC committed meat producers' levy funds to the programme. This programme developed on a variety of techniques that have been applied in the extension of research results and technologies to farmers.

The impact of integrated and consistent management advice on the transfer and adoption of 
information and farm profitability has been identified (McNeil et al. 1984).

The importance of good information and the role of group interaction in the quality of decisions made on sheep and beef farms has been illustrated through group farm monitoring (Webby \& Sheath 1991).

The outcome was to implement a programme that would increase farmers' awareness of manageable factors affecting their business, and motivate them to modify their systems to increase production and profitability, while managing risk.

Planning for the programme identified critical success factors as being:

- local ownership.

- quality information.

- a partnership of skills, expertise and experience.

Local ownership was considered to be important in developing the level of farmer commitment that would be necessary for a programme that would function over a 3- to 5-year period. It was also considered important that through local ownership, the group would be effective in managing real needs and in providing awareness and knowledge on issues for farmers.

Good information is essential for effective decision making (Webby \& Sheath 1991). Sheep and beef farms have tended to have inadequate or incomplete information for effective decision making. The programme sought to address this in two ways. Firstly, by illustrating the benefit of comprehensive information in effective decision making. Secondly, by applying effective and practical processes for identifying and obtaining information that is relevant for the management needs of a property.

Rather than maximising the amount of information able to be recorded, emphasis was placed on quality information - that which would be used in decision making and which was realistically able to be obtained by the farmer.

Development of a partnership involving the skills and experiences of farmers, researchers, consultants and agribusiness representatives was a goal.

It was considered that the potential benefit from this group composition would be enhanced knowledge, participation and decision making by the group.

To apply these principles, a monitor farm programme was developed. Key components of this were:

Monitor farmer/farm-a farming family and property identified by a community group as appropriate for the programme, having relevance to the circumstances of other farms in the district.

- Community Group-a multi-skilled group who would be committed to supporting the monitor farmer through the programme, providing a forum for group discussion, analysis and decision making. An initial commitment to a minimum of four meetings a year was required.

- Facilitator - a consultant responsible for supporting the community group in identifying and acting upon monitor farmer and group needs and skills.

- Farm plan - a farm business plan describing goals, objectives and action plans.

\section{Results}

\section{Number of monitor farms}

In August 1991 the MRDC undertook to fund 24 monitor farm programmes throughout New Zealand, with an equal allocation between the North and South Islands. Final regional locations reflected sheep and beef livestock numbers and trends, existing group monitor farms, and alternative or complementary programmes that were operating.

\section{Community group establishment}

Within each region chosen for implementation of the programme, farmers and industry personnel were invited to one or more meetings to discuss the programme and identify the level of support for establishing a community group. Farmer support for the concept was positive and enthusiastic.

A community group was established, with the initial task of selecting the monitor farmer and farm. Membership largely comprised farmers, researchers, veterinarians, financiers and fertiliser industry representatives.

\section{Selection of Monitor Farmer and Farm}

In the process of selecting the monitor farmer and farm, each community group considered:

- the predominant land use and livestock policies of the district.

- the mix of livestock policies and farm/farmer circumstances judged to have widespread relevance to the local farming community.

- the characteristics of the farming family and farm and the impact that the programme would have on them.

Farmer and farm selection involved both community and self-nomination. Following short listing, a subgroup was formed to make the final selection against established 
criteria. Some regions, especially where there is a diverse range of farming systems and livestock policies, experienced some difficulty during the selection process in meeting all the criteria established by the community group. Accordingly, the group reprioritised criteria or reinvited nominations.

The 24 monitor farms established were distributed throughout New Zealand (Figure 2).

Figure 2 Distribution of monitor farms throughout New Zealand

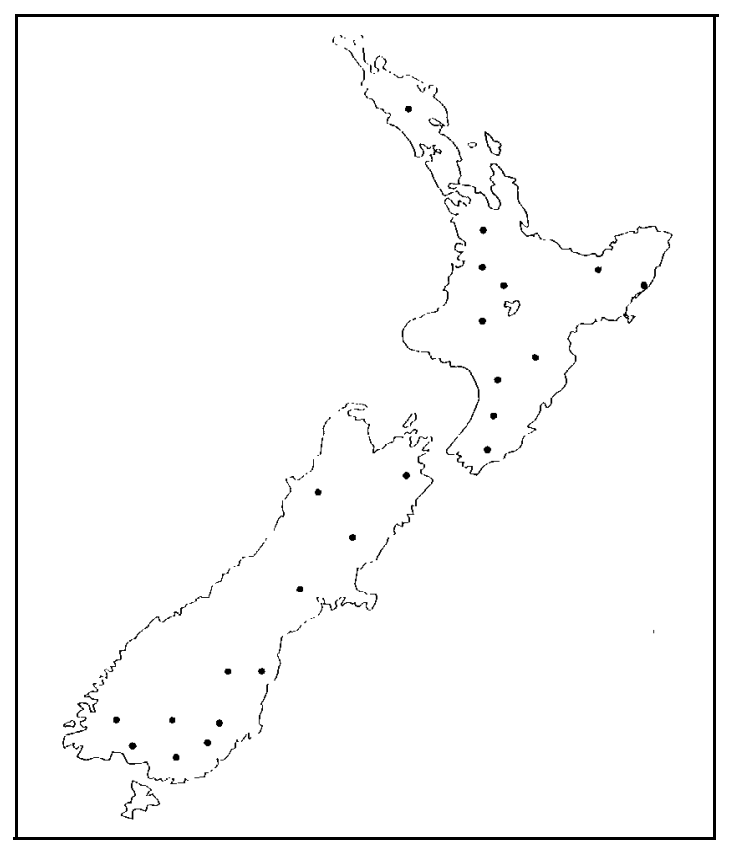

\section{Community group activities}

In the first year of operation, the priorities for each community group were to:

- develop their knowledge and understanding of the monitor farm.

- identify the objectives and factors important to the monitor farm family and farmer.

- create community awareness of the monitor farm programme and local monitor farm.

- identify information needs, and commence on-farm monitoring.

On-farm monitoring was encouraged and included the range of options reported by Webby \& Sheath (1991). Animal health and internal parasite surveillance of both sheep and cattle were incorporated on all properties at the start of the programme.

In addition, farm accounts were analysed both before and during the programme. Comparison was made against district averages for similar farm types. Monthly financial reporting and analysis was initiated where this was not currently operating.

Monitor farmers were encouraged to answer four questions about their farming business:

where am I now?

what could I achieve?

what do I want to achieve?

how do I achieve what I want?

From their responses, business plans have been prepared which will be used to guide future activities.

The management decisions made on the monitor farms are made in the same commercial environment experienced by other farmers. The programme does not underwrite risks. Commercial sponsorship of products for trialling or evaluation is considered inappropriate. While data collection and analysis is a key issue, it is not the intention of the programme to establish significant field trials on the monitor farms. It is considered that applied research should be undertaken in a more controlled environment and prior to on-farm decision making processes.

In September 1992, all community group members and monitor farmers were surveyed for their opinion on the relevance and value of the programme. This covered the period of establishment and initial operation of the programme. In summary, the survey indicated:

- groups in general consist of predominantly farmers with veterinarians and consultants in all groups. Scientists, meat companies and other agribusiness groups were sporadically represented.

- group size has prompted the formation of subgroups so that more effective debate of issues can occur. The community group delivers alternatives to the monitor farmer who has the final responsibility for decisions.

- $80 \%$ of respondents believed that the farms selected were typical and relevant. Many commented that it was nearly impossible to select a property completely typical of a district.

- monitoring activities undertaken on the farms were considered acceptable. Most groups were not confident to change monitoring criteria after only 12 months of operation.

- almost all farmers believed that they were more objective about their thinking as a result of having been involved in the monitor farm programme. Very few had responded to the experience by actually changing their management. The most common reason for this was that it was too early in the project to see the long term result of change. 
- the concept of a farm business plan was poorly understood.

- farmers received their information from newspapers, field days and other farmers. It was clear that people like to see the same information presented from several sources to add validity. Field days are highly valued as a method of putting information across "seeing is believing".

- the benefits of the programme included increased awareness of trace elements, pasture quality, internal parasite status and focused on the social interaction arising from being able to discuss problems with a like group.

By April 1993, all properties had hosted a minimum of one public field day.

Following each field day, a sample of attendees is surveyed for their opinion on the relevance and application of the programme and the nature of the benefit to them. Simple attendance figures have only limited value in assessing the value of the programme.

\section{Discussion}

The monitor farm programme has been operating for two years and farmers have endorsed the concept.

To improve the flow of information to farmers, the programme has sought to:

1. give the community and end users ownership of the project to ensure their involvement.

2. base the programme around an appropriate property selected by the community group.

3. utilise levy funding in a way which encourages meat producer involvement.

4. utilise group learning and discussion

5. establish base criteria about what can be introduced on the monitor farm to retain realism and avoid creating an experimental situation.

6. develop a farm business plan approach to interrelate the components of the farming business and give purpose to the incorporation of information and technology.

Each community group has responded uniquely to the monitor farm programme. This has been reflected in the variable time taken to develop a focus within the group, the range of monitoring activities implemented, and the different themes and issues addressed at respective field days.

Priorities for livestock policies and selling strategies have been reviewed, and the implications on feed management and quality of changes in livestock policies have been identified.

As benchmark information about each property is accumulated, the depth of understanding associated with decisions on each monitor farm will be enhanced.

While not all opportunities will meet the objectives of the monitor farmer, the monitor farm through field days and other activities provides a forum for other farmers to develop their understanding and appreciation of issues in an environment comparable to their own.

There is a need to develop effective techniques to assess the benefits of the programme. Continual review will enable the programme to deliver appropriate information and develop an improved process.

\section{REFERENCES}

McNeil, P.M.; Rhodes, A.P.; Willis B.H. 1984. A flock health and production service for New Zealand sheep farms. New Zealand Veterinary Services Council.

Scobie, G.M.; Eveleens, W.M. 1988. Agricultural Research, "What's it Worth"?MAF Discussion paper 1/86, June 1986.

Webby, R.W.; Sheath, G.W. 1991. Group monitoring, a basis for decision making and technology transfer on sheep and beef farms. Proceedings of the NZ Grassland Association 53: 13-16. 